\title{
How to motivate students to learn Metabolic Biochemistry in a Biomedical Sciences curricula
}

\section{Magda Carvalho Henriques, Margarida Fardilha}

Department of Medical Sciences, Institute of Biomedicine - iBiMED, University of Aveiro, Portugal.

\begin{abstract}
Teaching methodologies used in biochemistry classes at the University level are traditionally dependent on theorical classes. The assessment is usually based on written tests performed at the end of the semester. However, most students who learn metabolism by this traditional method consider the study of metabolic biochemistry a terrifying and unforgettable experience. Understanding biochemical metabolic pathways was the proposed goal of the Medical Biochemistry curricular unit. To this end, the multi-method active learning approach was used in order to increase students' motivation towards the learning process and to allow the development of skills associated with group conflict resolution, critical thinking and communication skills. Overall, students and learning facilitators were highly motivated by the diversity of learning activities, particularly due to the emphasis on correlating theoretical knowledge with human health and disease. As a quality control exercise, the students were asked to answer a questionnaire on their evaluation of the teaching/learning experience. Thus, the initial analysis of the student's perception questionnaires permits to conclude that the approach undertaken yields results that surpass the traditional teaching methods. Investing in preparing attractive and motivating classes increases students and teacher's general satisfaction and the learning/teaching process becomes more efficient.
\end{abstract}

Keywords: multi-method active learning approach; Metabolic biochemistry; student's motivation 


\section{Introduction}

Metabolism learning at the University level is traditionally dependent on theoretical classes. Usually, biochemical metabolic pathways are presented through lectures and the assessment is usually based on written tests performed at the end of the semester. Indeed, most students who learn metabolism by this traditional method consider the experience unforgettable and terrifying and do not understand the purpose of memorizing so many pathways and chemical structures.

Understanding metabolic pathways was the proposed goal of the Medical Biochemistry curricular unit (MBCU) in the Biomedical Sciences bachelor's degree at the University of Aveiro. For that, a multi-method active learning approach (MALA) (Fardilha, Schrader, da Cruz e Silva, \& da Cruz e Silva, 2010) was used in order to increase students' motivation towards the metabolic biochemistry learning process. Active learning approaches have been developed in higher education to improve the educational experience and outcomes in opposition to the traditional methods (Bate, Hommes, Duvivier, \& Taylor, 2014; Bonwell \& Eison, 1991; Norman \& Schmidt, 1992). In this approach, students are confronted with a variety of learning strategies allowing the development of skills associated with group conflict resolution, critical thinking and oral and written communication skills, where each person learns in its own way. Here students discover, research, process and apply information, and play a pivotal role on planning, monitoring and evaluating the educational method.

The MALA approach was previously applied in the Health Sciences Department at the University of Aveiro, in the MBCU (Fardilha, Schrader, da Cruz e Silva, \& da Cruz e Silva, 2010) and in the Pharmaceutical Drug Development curricular unit (Herdeiro, Teixeira Rodrigues, Ferreira, da Cruz e Silva, \& Fardilha, 2014). Authors of these studies concluded that MALA approach increased the research autonomy, synthesis, integration, student assessment and discussion of knowledge. Thus, the main goal of this study was the implementation of novel MALA strategies in the MBCU to achieve higher teachers' and students' motivation towards the learning experience and to improve students' educational outcomes.

\section{Methods and Results}

Given the complexity of the subject matter in the MBCU, various active learning activities were integrated (Table 1). Theorical classes were included to present the basis of metabolic biochemistry, in a strategy called "Teacher-centered learning". During these expository classes, students were encouraged to interact with the teacher by asking questions and after each class students were assessed by mini-questionnaires. These mini-questionnaires 
comprised several multiple-choice questions related to the topics exposed during the theorical classes.

Table 1. Learning approaches, skills developed, and assessment.

\begin{tabular}{cccc}
\hline $\begin{array}{c}\text { Learning } \\
\text { activity }\end{array}$ & $\begin{array}{c}\text { Learning } \\
\text { approaches }\end{array}$ & Skills developed & Assessment (\%) \\
\hline $\begin{array}{c}\text { 1. Theorical } \\
\text { classes }\end{array}$ & $\begin{array}{c}\text { Teacher-centered } \\
\text { learning }\end{array}$ & $\begin{array}{c}\text { Listening; information access; } \\
\text { reflection; discussion; } \\
\text { analysis; synthesis. }\end{array}$ & $\begin{array}{c}\text { Mini- } \\
\text { questionnaires } \\
(5 \%) \text {; final written } \\
\text { exam (60\%). }\end{array}$ \\
$\begin{array}{c}\text { Learning by } \\
\text { teaching }\end{array}$ & $\begin{array}{c}\text { Critical thinking; oral and } \\
\text { written communication skills; } \\
\text { capacity to explore; group } \\
\text { conflopment }\end{array}$ & $\begin{array}{c}\text { Poster: abstract } \\
(5 \%) \text { oral } \\
\text { presentation }\end{array}$ \\
& & & $\begin{array}{c}(10 \%) \text { and written } \\
\text { poster (20\%); }\end{array}$ \\
& & & Clinical cases: \\
& & & oral presentation. \\
\hline
\end{tabular}

Further, students were organized into small groups and asked to develop a poster on different subjects of the biochemical metabolism. Teachers and learning facilitators followed the project development by setting specific goals and activities with deadlines (abstract, objectives, written poster and poster oral presentation). Students were asked to first present the abstract and the objectives of the poster and an open discussion permitted clarification of students' doubts and problems encountered. Some weeks later, the posters were orally presented to the rest of class. Both activities were evaluated by teachers and learning facilitators. Teachers monitored each phase of the projects and maintained an open line of communication with the students. Given that various posters were presented to the whole class, this ensure that all students had the opportunity to learn and acquire relevant skills and knowledge. In particular, students were able to give feedback to their colleagues and to receive feedback from the teacher and peers. Posters were after presented in a conference organized by the Chemical Department of the University of Aveiro, called $10^{\text {th }}$ Biochemistry Day.

In a third learning activity, students, working in groups, were requested to solve and orally present clinical cases based on metabolic biochemistry disorders. Given that all the projects were presented to the class, this ensured that all students had the opportunity to learn all the subject matter and acquire relevant knowledge.

These strategies (poster and clinical cases) are called "learning by teaching" and allows students to teach new contents to each other, being accurately guided by teachers. Although 
the clinical cases activity was not included in the assessment, students were highly committed to do their best and, the resulting oral presentations were very good. The teacher and colleagues gave on time feedback on the students' presentations which seemed to be very helpful and appreciated.

Students' performance was assessed in different moments and using different assessment strategies: oral presentation of poster and clinical cases, mini-questionnaires after each expository class and a final test. Written material was routinely submitted for assessment, including the abstract and the poster. Communication skills were also practiced and evaluated during the oral presentations. Moreover, students were submitted to a final exam, which typically comprises answers in essay format spanning and integrating the metabolic biochemistry. Thus, student assessment was a continuous process involving students themselves. Together, all tasks applied in the MBCU allowed students to develop skills associated with critical thinking, information access, reflection, group conflict resolution, as well as oral and written communication skills.

As a quality control exercise, after the end of the curricular unit, students answered a questionnaire classifying the teaching/learning experience (Figure 1). Each topic to be assessed by the student on the questionnaire included several questions related to that issue, rated on a Likert (1-5) scale. Answers of "1" indicate the most negative response (unsatisfying), while " 5 " the most positive (excellent). The sum of the ratings for each question ( 1 to 5 ) was transformed into a percentage of the theoretical maximum. The results presented are the mean of the percentages for all the students. From the 30 students that participate in the MBCU in the curricular year 2017/2018, 20\% ( $n=6)$ did not answer the questionnaires. Results showed that the majority of the students were highly motivated due to the great diversity of the learning activities and considered that MALA is highly relevant for their curricula. 


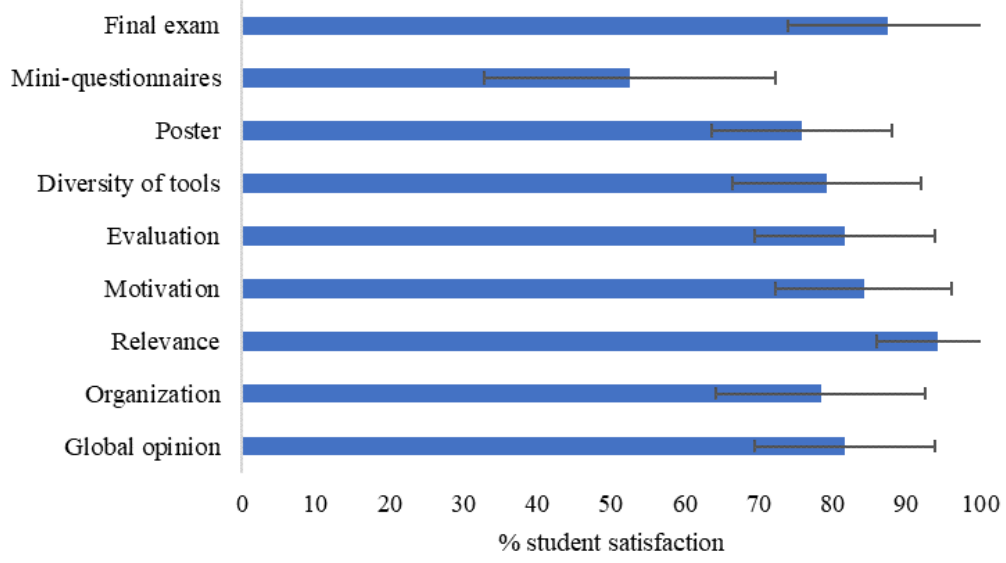

Figure 1. Results of the end of year questionnaire- based assessment of student satisfaction with their learning experience in the Medical Biochemistry unit.

Additionally, students were asked to indicate two positive and two aspects that could be improved in the MBCU. In general, they indicated that poster development and presentation was an excellent experience, in particular given that the poster had the purpose of being submitted to a conference.

The most negative aspect referred were the mini-questionnaires. Students point out that miniquestionnaires at the end of each theoretical class is very stressful. They suggest that the mini-questionnaires should be given at the beginning of the following theoretical class giving that time to consolidate the contents.

\section{Conclusion}

In the MBCU, a number of active learning techniques was incorporated to improve students' learning and motivation. The analysis of the student's perception questionnaires allows us to conclude that the MALA undertaken yields results that surpass the traditional teaching methods. Investing in preparing attractive and motivating classes increases students and teacher's general satisfaction and the learning/teaching process becomes more efficient. The positive results presented should encourage others in a similar situation to follow this approach.

\section{Acknowledgments}

The authors thank the Department of Medical Sciences of the University of Aveiro for the infrastructure support. The authors also thank the students of the Medical Biochemistry 
curricular unit of the Biomedical Sciences degree of the University of Aveiro (class 2017/2018) for being highly motivated and for motivating the teachers/facilitators. They were always avid for knowledge and ready to embrace new educational experiences. This work was also supported by an individual grant from FCT of the Portuguese Ministry of Science and Higher Education to M.C.H (SFRH/BD/131846/2017).

\section{References}

Bate, E., Hommes, J., Duvivier, R., \& Taylor, D. C. M. (2014). Problem-based learning (PBL): Getting the most out of your students - Their roles and responsibilities: AMEE Guide No. 84. Medical Teacher, 36(1), 1-12. https://doi.org/10.3109/0142159X.2014.848269

Bonwell, C. C., \& Eison, J. A. (1991). Active learning : creating excitement in the classroom. School of Education and Human Development, George Washington University. Retrieved from https://eric.ed.gov/?id=ED336049

Fardilha, M., Schrader, M., da Cruz e Silva, O. A. B., \& da Cruz e Silva, E. F. (2010). Understanding fatty acid metabolism through an active learning approach. Biochemistry and Molecular Biology Education, 38(2), 65-69. https://doi.org/10.1002/bmb.20330

Herdeiro, M., Teixeira Rodrigues, A., Ferreira, M., da Cruz e Silva, O., \& Fardilha, M. (2014). Multi-method Active Learning Approach: improving the educational experience in Pharmaceutical Drug Development. Indian Journal of Pharmaceutical Education and Research, 48(3), 16-25. https://doi.org/10.5530/ijper.48.3.4

Norman, G. R., \& Schmidt, H. G. (1992). The psychological basis of problem-based learning: a review of the evidence. Academic Medicine: Journal of the Association of American Medical Colleges, 67(9), 557-565. Retrieved from http://www.ncbi.nlm.nih.gov/pubmed/1520409 